\title{
CLOUD GIS AND 3D MODELLING TO ENHANCE SARDINIAN LATE GOTHIC ARCHITECTURAL HERITAGE
}

\author{
C.Pisu ${ }^{a^{*}}$, P. Casu ${ }^{\text {a }}$ \\ a D.I.C.A.A.R., Department of Civil, Environmental Engineering and Architecture, Cagliari University, 09124 \\ Cagliari, Italy-(cpisu, pcasu)@ unica.it
}

KEY WORDS: Cloud Computing, 3D Modelling, Photo-Modelling, Web GIS, Late Gothic Architecture, Sardinia.

\begin{abstract}
:
This work proposes the documentation, virtual reconstruction and spreading of architectural heritage through the use of software packages that operate in cloud computing. Cloud computing makes available a variety of applications and tools which can be effective both for the preparation and for the publication of different kinds of data. We tested the versatility and ease of use of such documentation tools in order to study a particular architectural phenomenon. The ultimate aim is to develop a multi-scale and multi-layer information system, oriented to the divulgation of Sardinian late gothic architecture. We tested the applications on portals of late Gothic architecture in Sardinia.

The actions of conservation, protection and enhancement of cultural heritage are all founded on the social function that can be reached only through the widest possible fruition by the community. The applications of digital technologies on cultural heritage can contribute to the construction of effective communication models that, relying on sensory and emotional involvement of the viewer, can attract a wider audience to cultural content.
\end{abstract}

\section{INTRODUCTION}

The cultural landscape describes the evolution of the relationship between people and nature through the generations. Carefully analyzed, it is a living archive from which you can learn and be inspired, in order to maintain harmony and balance of those living there. The study and preservation of historical-architectural heritage, alongside a proper promotion of the territory, could be a starting point for the development, in a perspective of sustainability and conservation of specific local diversity. (Jones, 2003)

The research is carried out within the international scientific debate on the use of innovative ICT (Information and Communication Technology) in the field of Cultural Heritage The ICT Program of the European commission has a section called Creativity that "explores the potential of information and communication technologies to enhance creative processes in general and in cultural and educational contexts in particular." (CORDIS, 2012)

This topic is very current and many scholars are interested in approaching it. "The main objective is to provide an international focal point for efforts in the improvement of all methods for surveying of cultural monuments and sites. The combination of all aspects of photogrammetry with other surveying methods is regarded as an important contribution to recording and monitoring cultural heritage, to the preservation and restoration of any valuable architectural or other cultural monument, object or site, and to provide support to architectural, archaeological and other art-historical research." (Patias, Santana 2011).

The application of these concepts on a specific field will allow us to determine and to deal with a methodology for the knowledge and the representation of architectural heritage. The methodology explicits the process of virtual reconstruction, data processing and dissemination.
The paper proposes a study of an important but not very well known Sardinian architectural heritage. We choose to document the portals of the late Gothic churches (15th- 17th century), through modern survey technologies and architectural photogrammetry, obtaining virtual models for dissemination on the web. The studied object is well suited to test the IBM (Image Based Modeling) (Fratus De Balestrini, Guerra, 2011), a tool that has recently proven to be extremely valuable in creating virtual 3D models derived directly from the photographic images of architectural elements. (Filippucci, M., 2010)

At the same time we generate a geo-referenced database containing all the information (historical documents, bibliographic references, photographs, drawings, etc.) related to the objects of study. The models, simplified and associated with georeferenced data, make up the Web GIS. It shows thematic maps and 3D models in a complex system developed with simple application available on the Cloud. In fact, the different types of data were organized in a shared system, using the tools offered by Google and some of its applications such as Google Earth and Google Fusion Tables. The ultimate goal is to get a system for dissemination of information about historical architecture on the Web.

If the purpose is cataloguing, GIS system is a good instrument because it brings useful reading elements. "It becomes an essential instrument if your aim includes preservation/management and fruition. If this is the starting point it is easy to figure out the right dimension between two prologs and up to now very different scientific methods; the history through cultural heritage and geographical and territory description locate" (Consorti, Di Renzo, Matani, 2008).

Web GIS and 3D modelling are valid instruments to document built heritage. We can cite some example applied to different cases of historic architecture. In particular: Apollonio, Gaiani, Corsi (2010) present an innovative semantic and parametric 
method to build 3D models to be used in cognitive-information systems, in particular they created a 3D Geodatabase of Palladio's works; (Ippoliti, Rossi, Meschini, Moscati, 2012) created a digital atlas for the documentation of cloisters and courtyards in Ascoli Piceno.

The digitization of cultural heritage is now at the center of an intense debate. It is one of the objectives of the European Commission. The attention on this topic is focused primarily on digitization of collections and objects preserved in libraries and museums, but also Architectural Heritage have his great cultural value. The digitization of data, that includes not only textual information, but also 3D models of these objects, is crucial. In fact, various causes, related to simple degradation or to more destructive events, can cause the loss of present assets. A work of this kind can help to raise awareness on historic architecture and at the same time to preserve the memory to bring them to future users. (Ikeuchi, Miyazaki,2008).

\section{OBJECT OF THE STUDY}

Sardinia, from the 14th to the 18th century, was part of the crown of Spain, and also on its territory developed the gothic building culture. The Mediterranean regions exhibit many specific achievements in Gothic architecture (Mira, Zaragoza Catalàn, 2003), but the study of this style was developed mainly for buildings situated in the Central European region, as France, Germany and Great Britain (Frankl, 2000). The architectures of Sardinia built between the 15th and the first half of the 17th centuries belong to the Mediterranean Gothic, and can be placed in the vein of the Spanish late Gothic. In this context, there are some other studies carried out in southern Italy (Cundari, 2007), particularly in Sicily (Inzerillo, 2008) (Santagati 2007).

During this period, this architectural style had reached the maximum spread in Sardinia, and were encoded particular forms which affected both the civil and religious architecture.

Gothic style come together with the Italian Renaissance and create a vocabulary of original shapes.

Portals, along with the vaults and the rose windows, are certainly among the strongest characteristic features of late gothic religious buildings. Notable examples of these elements are found throughout the island (Casu, Pisu, 2012).

This study aims to deepen the knowledge about some particular features in the Sardinia late-gothic buildings. We choose portals because they combine all the typical forms developed by picapedres (catalan stonemasons) (Segni Pulvirenti, Sari, 1994). The portal is sometimes the only element still intact inside a façade maybe rebuild at later dates. The Sardinian late Gothic church has a very simple scheme. It is set on a rectangular plan with a single nave. The presbytery is cross vaulted (simple or stellar vault) and cross vaulted chapels are open along the nave sides (Serra, 1966). Access to the church is in most cases done through a single opening, a portal. In the oldest system, the portal with the rose window was the only element that gave light to the nave, since small round windows of the side chapels were not always present. The portal is located into a façade which generally has these characteristics: flat, rectangular shape bounded by buttresses (which actually do not have a static function, because usually the roof of the hall is gabled), bell tower on the right side.

Many of the late-gothic churches we found in Sardinia, have been modified and expanded over the centuries, so the still preserved original features are reduced to a few parts.
The portals are certainly among the strongest characteristic that these buildings still retain. They were unknown, especially those located in minor contexts, but after several years of study in this area, we carried out a database containing information about many buildings located throughout the region and that contain such features.

\section{METHOD}

The research is carried out within the international scientific debate on the use of ICT (Information and Communication Technology) in the field of Cultural Heritage and it is structured according to the principles of the London Charter (Denard, 2009). During the research development, the application and the verification of these principles have allowed us to work out a methodology for knowledge, representation and divulgation of architecture.

The research has been organized into several phases:

- identification of buildings with significant features based on analysis of census data;

- collection of historical documents in the archives (bibliographic sources, photographs, drawings, etc.);

- cataloging, digitization, organization of collected materials in a database;

- collection of metric data and photos in order to make 3D models of the buildings;

- $\quad$ image processing using IBM (Image Based Modeling) software in order to create detailed models of portals;

- processing of the obtained mesh and simplification of the 3D models;

- creating of Web GIS combining georeferenced data and $3 \mathrm{D}$ models.

The whole process of modeling is already designed for the future dissemination on the web, so we chose to work with cloud computing and free applications, that allowed us to achieve this goal in a short time and low cost. In this way we were able to encode a methodology applicable in other similar contexts.

\section{APPS, SOFTWARE AND CLOUD COMPUTING}

"The actions of conservation, protection and enhancement of cultural heritage are all founded on the social function that can be reached only through the widest possible fruition by the community. The applications of digital technologies on cultural heritage can contribute to the construction of effective communication models that, relying on sensory and emotional involvement of the viewer, can attract a wider audience to cultural content" (Ippoliti, 2011).

Today, possibilities offered by cloud computing (Mell, Grance, 2011) makes available a variety of applications and tools which can be effective both for the preparation and for the publication of all kinds of data. The service models of cloud are three: Software as a Service (SaaS), Platform as a Service (PaaS), Infrastructure as a Service (IaaS). The applications used in this specific research are systems SaaS (Software as a Service) in which the user can use the applications running on a cloud 
infrastructure. These applications are in fact accessible through a Web browser, or the interface of a program.

In this study we used SaaS applications for the construction of the geo-referenced data and for the creation of 3D detailed models of the portals, obtained from a set of unordered photos. Other processes were conducted offline, such as 3D models of the buildings, using Sketch Up. We designed the entire data system to be spread on the web by systems of maps sharing based on Google Maps or Google Earth..

\section{DATABASE AND WEB GIS}

Here we propose the first results of the investigations that led to the creation of a regional database in which the buildings have been identified and divided by type of portal.

We recorded 73 entrance portals. They belong to buildings that often, in addition to the portal, retain other characteristic elements of Sardinian late Gothic: the vaults, the bell tower, the rose window. We divided portals into several distinct types, mainly according to the geometric shape of the opening: pointed arch, round arch, arch with three centers, lintel or other types not related to previous ones, characterized by a multilinear geometry, which, in some cases, it resolves over a "flame arch" (Pisu, 2010).

\begin{tabular}{lll}
\hline Type of portal & $\begin{array}{l}\text { Number of documented } \\
\text { cases }\end{array}$ & $\begin{array}{l}\text { total } \\
\text { towns }\end{array}$ \\
\hline pointed arch & 29 & 26 \\
\hline round arch & 26 & 26 \\
\hline lintel & 9 & 9 \\
\hline $\begin{array}{l}\text { arch with three } \\
\text { centers }\end{array}$ & 5 & 5 \\
\hline other & 4 & 4 \\
\hline
\end{tabular}

Table 1. Portals distinct according to the geometric shape.

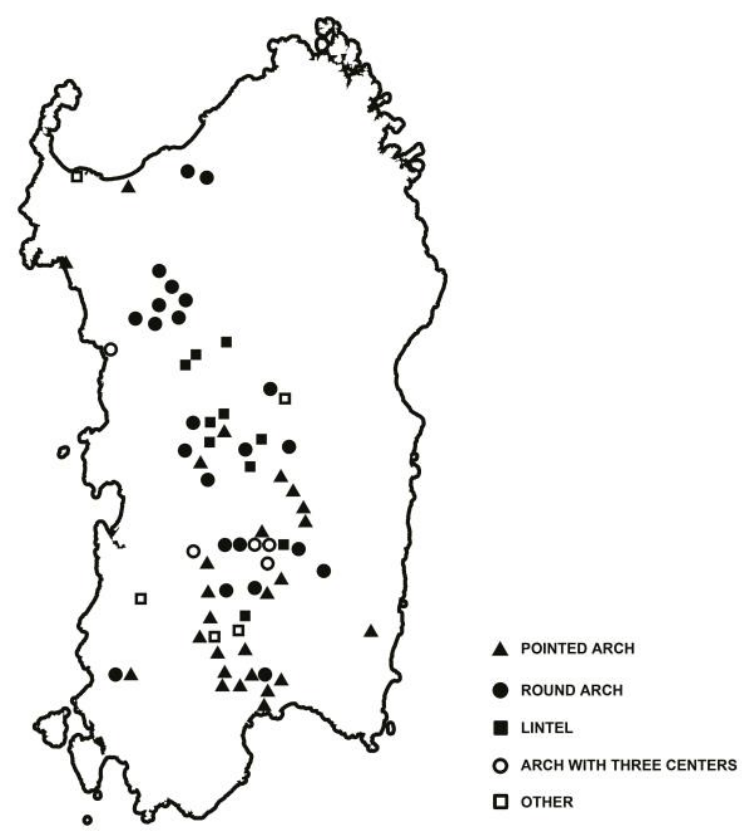

Figure 1. Location of the portals, distinct according to the geometric shape.
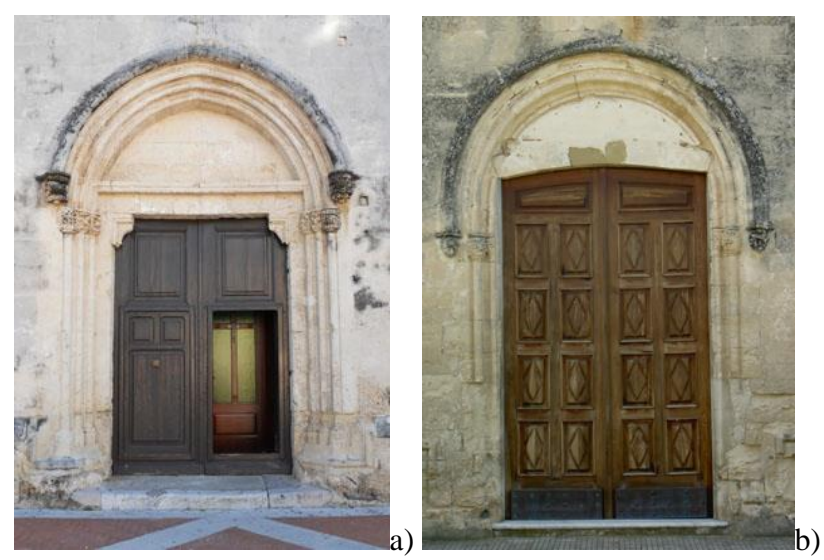

Figure 2. Example of portals: a) pointed arch, San Pietro Assemini, Ca; b) round arch, Beata Vergine Immacolata, Barumini (VS).
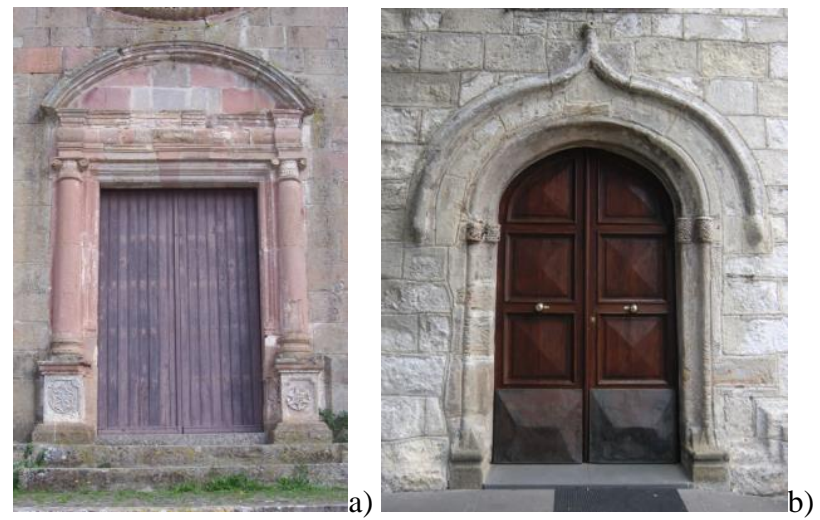

Figure 3. Example of portals: a) lintel (influenced by Italian Renaissance), San Mauro, Sorgono (Nu); b) arch with three centers and "flame arch", San Vincenzo, Orroli (Ca).

The database contains all the information we founded for each portal, in particular:

- The location (divided into geographic coordinates and address);

- The name of the building to which they belong;

- The exact date, if known, or alternatively, the century of edification;

- The building materials;

- The conservation status;

- The geometric classification;

- Links to external resources, ie. images, 3D model of the building, 3D model of the portal.

In this phase we proceeded to a first sieve of information collected in order to prepare the geo-referenced database and external data linked to it. In the second phase we worked on the technical aspects related to the organization of tables and the definition of feature classes. The result is the creation of layers of information that would be available for the production of thematic maps.

To create the database we used Google Fusion Tables, an application created for sharing data organized in tables. It allows to enter the geographic coordinates for each inserted record. In this way the geocoded data included in Fusion Tables can be exported in a static or dynamic way to be viewed in Google Earth. In the first case we can create a .KMZ file that can be uploaded in Google Earth and customized according to the graphic styles functions of the application. In 
the second case we can create a .KML file that is a link to the table. In this way, unlike the static situation, if the data in the table are changed, they are automatically updated even in the Google Earth view.

Fusion Tables allows the creation of complex tables (see fig. 4) in which you can add not only text data but also images, geographic coordinates, symbols for displaying data on a map and links to external data. For each field into the table, you can apply filters to search for records inserted both in the table view and in map view. The filters thus allows easy interrogation of the database and the consequent creation of thematic maps.

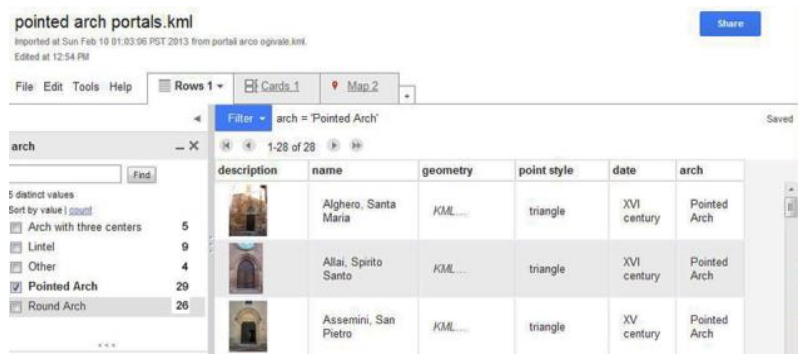

Figure 4. Screenshot of the table created by Google Fusion Tables.

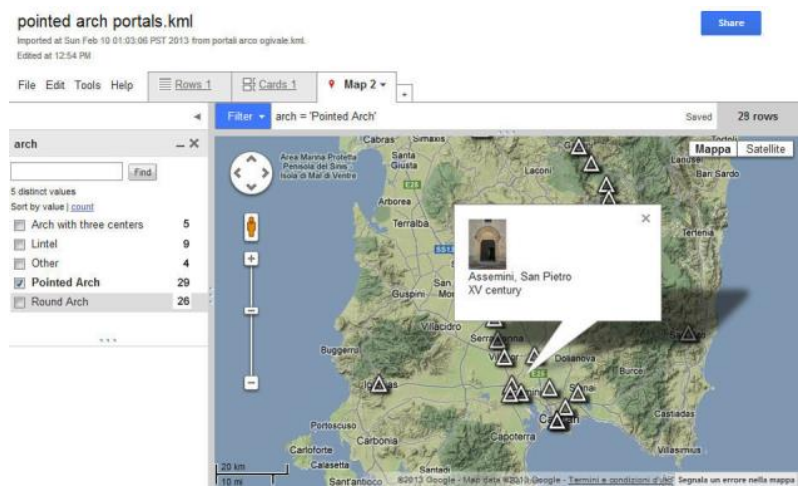

Figure 5. Screenshot of the map created by Google Fusion Tables.

\section{3D MODELLING}

For the documentation of the buildings we combined different methodologies of drawing. At first, we developed the model of the entire building through the use of software Trimble Sketch up that would allow the creation of a lightweight model for dissemination on the web. We created the 3D model starting from existing drawings. We verified the accuracy of the dimensions shown in the drawings. Then we modeled only the outer casing, in order to obtain a lightweight file.

The 3D models are saved in KMZ format to be displayed in Google Earth and published in the 3D Warehouse. To get to the publication of the models on the 3D Buildings layer in Google Earth, we made the operations of optimization models. The 3D model, intended for publication on this level, requires at the same time light weight and accuracy. The specifications to be met can be summarized as follows: geometric simplicity (few surfaces), completeness and accuracy of photorealistic textures, correct georeferencing. So, we opted for a high simplification of the model without, however, neglecting those specific characters and geometric relationship between the parties, which characterize the real object. At this stage we have chosen to omit the modeling of details such as cornices, projecting elements and decorations. They have been implemented through a careful choice of textures. This choice has allowed to reduce to a minimum the surfaces constituting the models so as to achieve the standard of sharing dictated by 3D Warehouse. The rules for accepting state that the model complete with photorealistic textures should not exceed 10 $\mathrm{Mb}$. For this reason, the texture must have a maximum resolution of $1024 \times 1024$ pixels.

In the second phase of the work, a more detailed model of the portals was instead created with 123D Catch by Autodesk, an Image Based Modeling (IBM) system available free, that operates on the cloud. By using the computing power of the cloud the software finds the correspondence between pictures of an object bringing back the 3D model in the form of mesh. It combines an app and a web-service. It is a web-based application that requires a few simple steps to produce a mesh from a set of not oriented photos. The Autodesk 123D Catch software operates in cloud computing for the computation of correspondences between the images and the creation of triangulated mesh. The software also creates the texture of the mesh using the referenced photos. The app also permit to scale the model and the definition of a coordinate system to orient the mesh. Then, we processed the obtained mesh with a 3D modeling software in order to simplify the geometry. Finally we obtained a model that meets the standards for sharing on the web.
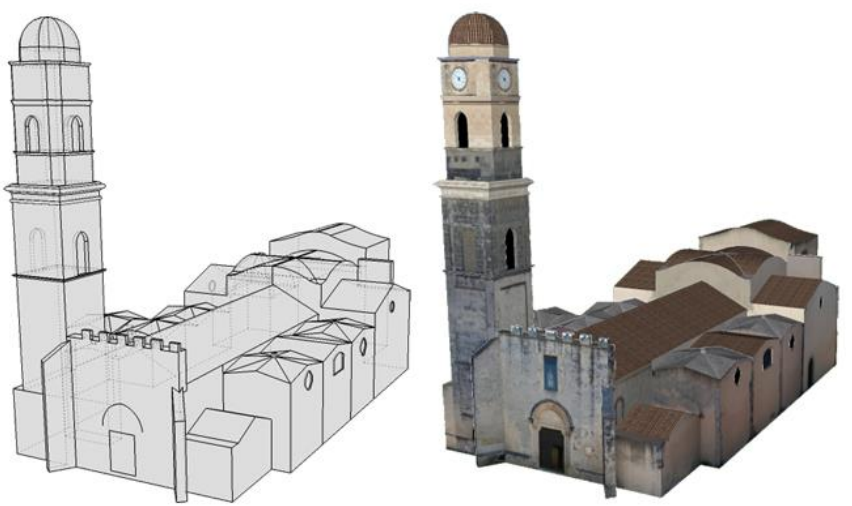

Figure 6. Example of one of the studied buildings: model of the church of San Pietro in Assemini, obtained with Trimble Sketchup.
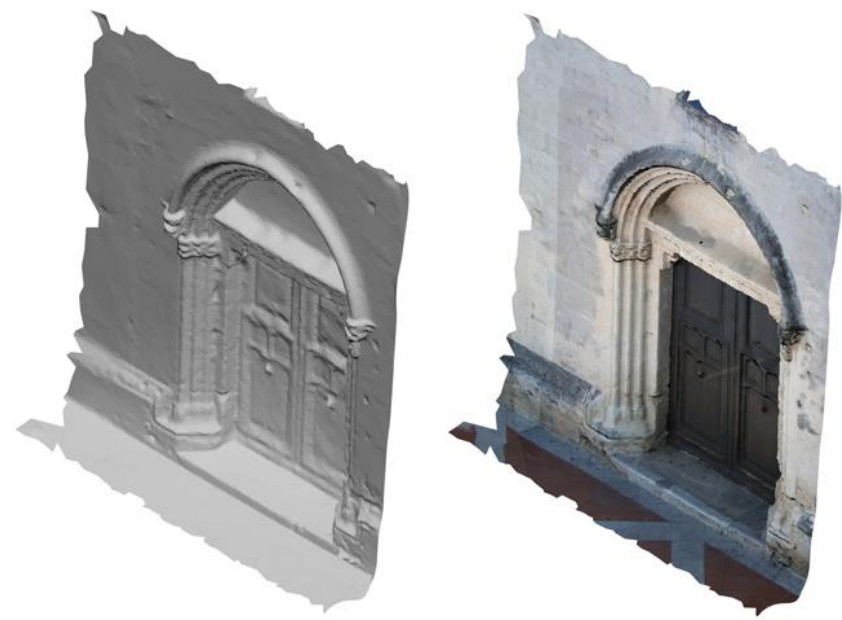

Figure 7. Model of the portal of San Pietro in Assemini, obtained with Autodesk 123D Catch. 


\section{DATA SHARING}

In the last phase of sharing the work, we analyzed the relationships between the different components of the system. Through the layering and using query filters we were able to highlight the expected results. As mentioned above, we have entered the data directly in Google Fusion Tables, providing a field for entering the coordinates of the points associated with that data. For each row in the table we determined the style of the point that will appear on the map and other formatting information. Each point on the map that locates a portal is associated with a text box, which is visible if you click on the placeholder. Within this table we have included the dating, the description of the portal and links to external resources such as 3D models and more complex and detailed documentation. In fact the purpose is to create a light map that allows the access to different resources that deepen the argument in a dynamic way. From the web GIS the user can choose paths according to different selected parameters. The user can display the custom map according to his search criteria, simply by setting the query to the system.

For example, applying some filters, it is possible to see portals with pointed arch in the Cagliari area. They are the most common and most representative of late Gothic architecture in Sardinia. Albeit in different state of preservation, they appear similar in many aspects: the rectangular opening is framed by pilasters with cylindrical capitals, and surmounted by a pointed arch with eyebrow. Ashlars of the lintel are always processed to form a protruding molding that emphasizes the rectangular aperture, separating it from the decorative pointed arch. They are also made of the same stone typical of the area: the limestone of Cagliari.

The variety of data entered into the database, allows us to select information in different ways. The application therefore allow different uses by a various audience: the architect that needs specific technical information relating to the type, date, material, state of conservation, etc.; the student that makes a specific search in architectural field; the tourist who wants to find a cultural path in an area that he doesn't know. Future development could occur in the tourism sector also determining travel time in relation to the places to visit.

Although the products of this work are very different in nature, they are connected following the rules of link sharing on the web. In fact, the end user could get to display all of the work in different ways. One way would be to access the system from the models in the 3D buildings layer in Google Earth, after they have been accepted and validated. In fact, in the descriptive text associated with such models is provided a link to the entire database. This is the easiest route but less structured. In addition, it has a limit, because if other users create higher quality models, these will replace the existing ones on the 3D Buildings layer of Google.

The other path, which corresponds to the final way of the data dissemination is currently in development. It consists of the prior creation of a dedicated website where, starting from the database, you get to all specialized contents. In this case the starting point is the map with geo-referenced points. Each point is connected to a text box that contains the links to 3D models. At this stage, part of the work can be found on the following link to Google 3D Warehouse:

http://sketchup.google.com/3dwarehouse/details?mid=f807a17 926f220f1bbbe66f8f79d0879\&prevstart $=0$.

Soon the models will also be available on the 3D layer of Google Earth.

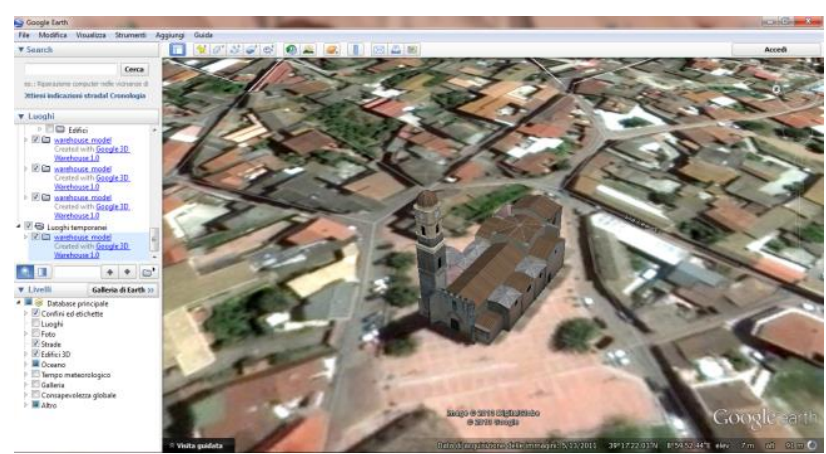

Figure 8. The church of San Pietro in Assemini, in the 3D layer of Google Earth.

\section{RESULTS AND CONCLUSIONS}

This research provides a method to study architectural heritage by using cloud computing and user friendly applications.

The speed of this method has enabled the accurate documentation of some buildings and portals. The results obtained are objectively comparable and the method could be applied in any context. We tested the applications on the specific case at different detail scale and we performed a comparison between various architectural elements, in particular between portals, highlighting similarities and differences that with other systems would be long and laborious to obtain. Moreover, using Fusion Tables we could share not only the database tables, but the map associated with it, created on the Google Maps interface and also viewable on Google Earth, in order to reach a wide audience. Using these applications we have agreed to make available for free the objects created. However, both the database and the model cannot be modified prior permission of the author.

The aim of this research is to give back an historical and social value to some architectures situated in the cities but especially in the small villages of the island. This intrinsic value of cultural heritage should be first of all felt by people who live there. Today ICT, if well implemented, allows the dissemination and the communication of digital content in a simple, straightforward way. Therefore, the knowledge of the history of some buildings becomes a common cultural heritage, and not an exclusive prerogative of scholars or experts. We tried to achieve this goal through the use of the tools provided for free in the cloud where anyone can access. The information system has made it possible to achieve some important results related to localization and visualization of portals, allowing us to connect various data on a single platform that can be used in a simple and immediate way. These data will be made freely available by entering the final link .KMZ file on a website, currently under construction. In this way this work will be viewed by any web user who has any interest in this field. In addition, using the Google API, we can greatly improve the display and customization of the maps in order to make more immediate and easier the use of the data.

We designed the system so that it would became a tool for immediate display of many different data. It can serve as a basis from which to formulate planning hypotheses, establishing a bottom-up dialogue involving all actors that can contribute to the enhancement of cultural heritage. The spread of the studies to a wide audience could have an impact on the increase in cultural tourism, but also in sustainable land 
management. Such a system could also foster closeness of young people, the major users of new technologies, to cultural heritage and will be encouraged them to take an interest in their culture in a spontaneous way, rediscovering their villages and their cities.

\section{References}

Apollonio F.I., Gaiani M., Corsi C., 2010. A semantic and parametric method for 3D models used in 3D cognitiveinformation system. In: Future cities. 28th eCAADe 2010 Conference, ZURICH, ECAADE - ETH Zurich, pp. 863 -872 .

Casu P., Pisu C., 2012, Le volte nervate del tardogotico sardo. Disegnarecon 5(9) Jun. 2012, pp. 65-72 (2012). 〈http://disegnarecon.unibo.it/article/view/ 3154/2549> (15 June 2013)

Consorti V., Di Renzo F., Matani L., 2008, Sistemi per la documentazione e gestione dei beni culturali in ambito WEBGIS, atti $12^{\circ}$ Conferenza Nazionale ASITA, l'Aquila 21-24 ottobre 2008, p. 833 .

\section{CORDIS}

http://cordis.europa.eu/fp7/ict/creativity/creativity_en.html (01 July 2013)

Cundari, C., (editor), 2007, L'architettura di età aragonese nell'Italia centro-meridionale. Rapporto conclusivo. Vol. 9, Kappa Edizioni, Roma.

Denard H. (editor), 2009, London Charter, http://www.londoncharter.org/fileadmin/templates/main/docs/1 ondon_charter_2_1_en.pdf, (19 June 2013).

Filippucci, M., 2010, Nuvole di pixel. La fotomodellazione con software liberi per il rilievo d'architettura. Pixel clouds. Free photomodelling software for architectural survey, Disegnarecon $\begin{array}{lllll}\text { Vol. } & 3, & \text { n. } & 6 & \text { (2010) }\end{array}$ http://disegnarecon.unibo.it/article/view/2081/1468 (01 July 2013)

Frankl, P., 2000, Gothic Architecture, Yale University Press.

Fratus de Balestrini, E., Guerra, F.: New instruments for survey: on line software for $3 \mathrm{~d}$ reconstruction from images. The International Archives of the Photogrammetry, Remote Sensing and Spatial Information Sciences, XXXVIII-5/W16, pp. 545552. (2011)

Jones, M., 2003, The concept of cultural landscape: disclosure and narratives. Palang, H., Fry, G. (editors): Landscape Interfaces: Cultural Heritage in Changing Landscapes, Vol. 1, Springer, pp.21-52.

Inzerillo, L., 2008, Il Gotico Chiaramontano, Aragonese e Catalano nella Sicilia occidentale. Monofore, bifore, trifore e cappelle interne. Palermo. Edizioni Caracol.

Ippoliti,, E., Rossi, D., Meschini, A., and Moscati, A., (2011) An approach towards the construction of a digital atlas for the documentation of cloister and courtyards in Ascoli Piceno, Int. Arch. Photogramm. Remote Sens. Spatial Inf. Sci., XXXVIII5/W16, 231-238,

Ippoliti E., 2011, Media digitali per il godimento dei beni culturali. Disegnarecon, 4(8), Dec. 2011. pp. 2-13. http://disegnarecon.unibo.it/article/view/2564 (25 June 2013)

Ikeuchi, K.; Miyazaki, D., 2008, Digitally Archiving Cultural Objects. Springer.

Mell P., Grance T., 2011, The NIST definition of Cloud Computing, NIST Special Publication 800-145 http://csrc.nist.gov/publications/nistpubs/800-145/SP800145.pdf (19 June 2013).

Mira, E., Zaragoza Catalàn, A. 2003, Una Arquitectura gotica mediterranea. Comunidad valenciana, Catalogo de la Exposiciò. 2 vols. Valencia, Conselleria de Cultura y Educaciò.

Patias P., Santana M., 2011, Introduction to Heritage Documentation, in Stylianidis E., Patias P., Santana M. (editors), CIPA heritage documentation. Best practices and applications, UNESCO - ICOMOS Documentation Centre, Paris, p. 9.

Pisu C, 2010, Geometric analysis of gothic openings with ogee arch, Proceedings of The 14th International Conference on Geometry and Graphics, Edited by Inter-national Society for Geometry and Graphics, Kyoto, p.352.

Santagati, C., 2007, Gli ultimi bagliori del gotico di influenza ispanica in Sicilia: la torre del Carmine e il campanile del Duomo a Piazza Armerina, in Luigi Andreozzi (a cura di), L'architettura di età aragonese nell'Italia centro-meridionale, Verso la costituzione di un sistema informativo territoriale documentario iconografico, L'architettura di età aragonese nel Val Demone, vol 5, Aracne editrice, Roma, p. 43-52.

Segni Pulvirenti F. Sari A., 1994, Architettura tardogotica e d'influsso rinascimentale, Ilisso, Nuoro.

Serra R., 1966, Le parrocchiali di Assemini, Sestu e Settimo San Pietro. Note per una storia dell'architettura tardogotica in Sardegna. Atti del XIII Congresso di Storia dell'Architettura. Soc. A.B.E.T.E. Roma. 